\title{
Study of dehydroxylated-rehydroxylated smectites by SAXS
}

\author{
F. Muller, C.-H. Pons and A. Papin \\ Institut des Sciences de la Terre d'Orléans (ISTO), CNRS, Université d'Orléans, \\ $1 A$ rue de la Férollerie, 45071 Orléans cedex 2, France
}

\begin{abstract}
Montmorillonite and beidellite are dioctahedral 2:1 phyllosilicates. The weakness of the bonding between layers allows the intercalation of water molecules (disposed in layers) in the interlayer space. The samples studied are constituted of $c v$ layers ( $c v$ for vacant octahedral sites in $c i s$ positions). They have been dehydroxylated. This is accompanied by the migration of the octahedral cations from former trans-octahedra to empty cis-sites therefore the layers become $t v$ (vacant site in trans position). To characterize the stacking of the layers, SAXS (Small Angle Xray Scattering) analyses have been investigated in natural $(N)$ and after a dehydroxylation-rehydroxylation cycle (R) states. The SAXS pattern modelisation for $\mathrm{Na}$-exchanged samples in the $\mathrm{N}$ state shows that the layers stack in particles with well defined interlayer distances $d_{00 /}$, corresponding to 0 water layer, 1 water layers and 2 water layers. The dehydroxylation-rehydroxylation cycle increases the proportion of interlayer distances with zero water layer and the disorder in the stacking. The decreasing of the disorder parameter with the proportion of tetrahedral charge in the $\mathrm{N}$ and $\mathrm{R}$ sample shows that the distribution of the water layers depend on the localization of the deficit of charge
\end{abstract}

Résumé: Les montmorillonites et les smectites sont des phyllosilicates 2:1 dioctaédriques. Les liaisons cntre feullets sont suffisamment faıbles pour permettre l'insertion, dans l'espace interfoliaire, de molécules d'eau qui se disposent en couches. Les échantillons étudiés ont des feullets cis-vacants (le site octaédrique inoccupé est en une des deux positions "cis") Ils ont été deshydroxylés Ceci s'accompagne d'une migration cationique, à l'intérieur des couches octaédriques, des sites trans vers les sites cis et le feuillet devient trans-vacant. Des expériences de Diffusion $X$ aux Petits Angles (DPA) ont permis de caractériser l'empilement des feuillets. La modélisation des diagrammes de DPAX met en évidence, pour les échantillons sodique non trattés, des empilements de feuillets formant des particules avec des distances interlamellaires à 0,1 et 2 couches d'eau. Après le cycle de déshydroxylation-réhydroxylatıon, la proportion de feuillets avec une distance interlamellaire correspondante à zéro couche d'eau et le désordre dans l'empilement des feullets augmentent. La décroissance du paramètre de désordre avec la proportion de charges tetraédriques montre que l'organisation des couches d'eau dépend de la localisation du déficit de charge.

\section{INTRODUCTION}

Montmorillonites and Beidellite (smectite family) are dioctahedral 2:1 phyllosilicates of idealized structural formula :

$$
\mathrm{M}_{\mathrm{x}+\mathrm{y}}\left(\mathrm{Mg}, \mathrm{Fe}^{\mathrm{II}}\right)_{\mathrm{x}}\left(\mathrm{Al}, \mathrm{Fe}^{\mathrm{III}}\right)_{2-\mathrm{x}} \mathrm{Si}_{4-\mathrm{y}} \mathrm{Al}_{\mathrm{y}} \mathrm{O}_{10}(\mathrm{OH})_{2}
$$

where $\mathrm{M}^{+}$is the interlayer cation which compensates the negative charge of the layer arising from cation substitutions inside the layer. The 2:1 notation means that layers are formed of two sheets of tetrahedra sandwiching a sheet of octahedra (Fig. 1a). Dioctahedral means that in the octahedral sheet, only two of the three sites per one half unit-cell are occupied.

The relative weakness of the bonding between layers, through the interlamellar cations $(\mathrm{Na}, \mathrm{Ca}, \ldots)$ authorizes intercalation of various molecules and in particular water molecules. The water molecules are organized in layers in the interlayer space and generally montmorillonite and beidellite minerals consist in interstratified samples in which the number of water layers characterize each type of layer (Fig. 1b). For example, in air dried state, the Wyoming Na-montmorillonite correspond of hydration states of 0,1 or 2 water layers. 
Generally, in the natural montmorillonite or beidellite, the vacant site is in one of the two cis positions ( $c v 1$ or $c v 2$ layer, $C 12(1)$ space-group, Fig. 2a, [1]). After a treatment consisting of dehydroxylation (replacement of the adjacent hydroxyls of the octahedral sheet by a residual oxygen atom $\mathrm{O}_{\mathrm{r}}: 2(\mathrm{OH}) \rightarrow \mathrm{H}_{2} \mathrm{O}(\uparrow)+\mathrm{O}_{\mathrm{r}}$ ) and rehydroxylation (regain of the hydroxyls : $\mathrm{O}_{\mathrm{r}}+\mathrm{H}_{2} \mathrm{O} \rightarrow 2(\mathrm{OH})$ ), the layers become trans vacant ( $t v$ layer, $C 12 / m(1)$ space-group, Fig. 2b, [2, 3]). This transformation results of the migration of the octahedral $\mathrm{Al}^{3+}$ cations during the dehydroxylation [1]. In addition to the changing in the position of the vacant octahedral site (trans to cis), the dehydroxylation-rehydroxylation cycle induces two other structural effects. First is the increasing of the $\mathrm{OH}-\mathrm{OH}$ distance, which is longer in $c v$ layers in comparison with $t v$ ones (see Fig. 2). Second is the changing of the apparent interlayer distance $d_{a p}(001)[3,4]$.

Recent studies [3] have shown that, in Wyoming Na-montmorillonite, the distribution of water layer in the interlayer spaces changes in small proportion after a dehydroxylation-rehydroxylation cycle which modify the hydration properties of the sample. The aim of this work is to determine the number and proportion of water layers in the natural state $(N)$ and in the rehydroxylated state $(R)$ of three samples differing by the localization of the deficit of charge.

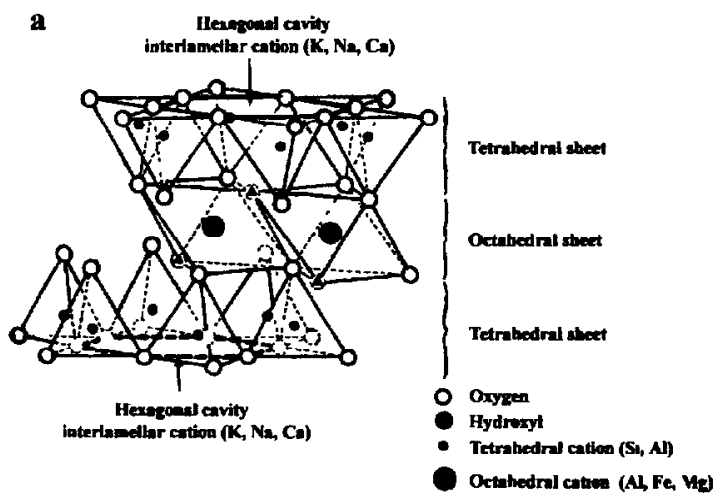

b

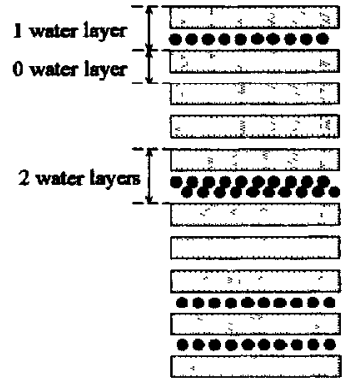

Figure 1: Schematic representations of a 2:1 layer (a) and a stacking of interstratified layers (b).

Représentation schénatique d'un feuillet 2:1 (a) et d'un empilement de feuillet interstratifiés (b).

$\mathbf{a}$

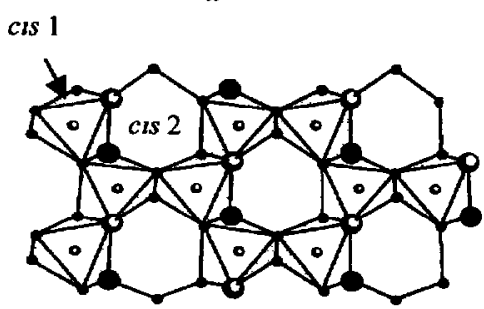

- Oxygen

- Octahedral cation

Lower $\mathrm{OH}$

isper $\mathrm{OH}$ b

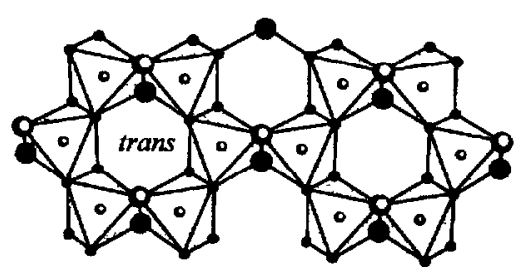

Figure 2 : Schematic representation of an octahedral sheet in the case of cis-vacant layers (a) and tans-vacant layers (b). Représentation schématique de la couche octaédrıque d'un feuillet cus-vacant (a) et d'un feuillet trans-vacant (b).

\section{METHOD}

To determine the water contents in the interlayer space a simulated method has been used. The model is based on the notion of particle and of particle internal structure (Fig. 3, [4, 5]). The basic components of all 2:1 phyllosilicate structures are the layers. One particle consists of a stacking of $M$ parallel layers in which interlayer spaces can be different from one layer to another (Fig. 1b). 


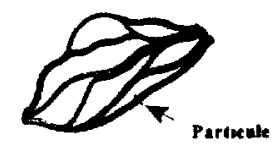

Level 2- etgeregate

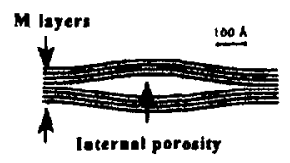

Level 1: pardenle

Figure 3 : Schematic representation of two structural levels in a clay-water system. the particle level (level 1) and the aggregate (level 2).

Représentation schématique de deux niveaux structuraux dans un système argileux . la particule (niveau 1) et l'agrégat (niveau 2).

\subsection{Intensity calculations}

In the case of a heterogeneous clay system with water content, a particle can be consisted with two swelling phases in which interlayer spaces can be different from one layer to another. The distance distribution inside a phase is totally random. If we assume that $[4,6]: 1)$ layers have a great lateral extension and particles have all possible orientations in space, 2) all the layers in a given phase have the same structure factor, then the matrix expression of the scattered intensity is $[4,7]$ :

$$
I(s)=\frac{1}{s^{2}} \sum_{M} \alpha(M) \operatorname{Spur} \times\left\{\operatorname{Re}\left\{[F][W\}\left\{[I]+2 \sum_{n}\left(\frac{M-n}{M}\right)[Q]^{n}\right\}\right\}\right\}
$$

where $s$ is the modulus of the diffraction vector $(s=2 \sin \theta / \lambda, \lambda=$ wavelength); $\alpha(M)$ the distribution of the number of layers per particle; Re means the real part of the final matrix; Spur, the sum of the diagonal terms of the real matrix; $M$ the number of parallel layers per stack; $n$, an integer varying between 1 and $(M-1),[F]$ the structure factors matrix; $[I]$ the unit matrix; $[W]$ the diagonal matrix of the proportions of the two phases, and $[Q]$ the matrix representing the interference phenomena between adjacent layers. $[Q]$, $[F]$ and $[W]$ have the following forms :

$$
\begin{gathered}
{[Q]=\left|\begin{array}{cc}
P_{A, A} \sum_{1} p(A)_{,} \exp \left(2 \pi i s d(A)_{1}\right) & P_{A, B} \sum_{J} p(A)_{,} \exp \left(2 \pi i s d(A)_{t}\right) \\
P_{B, A} \sum_{J} p(B), \exp \left(2 \pi i s d(B)_{J}\right) & P_{B, B} \sum_{J}^{\prime} p(B)_{,} \exp \left(2 \pi i s d(B)_{J}\right)
\end{array}\right|} \\
{[F]=\left|\begin{array}{ll}
F_{A}^{*} F_{A} & F_{A}^{*} F_{B} \\
F_{B}^{*} F_{A} & F_{B}^{*} F_{B}
\end{array}\right| ;[W]=\left|\begin{array}{cc}
W_{A} & 0 \\
0 & W_{B}
\end{array}\right|}
\end{gathered}
$$

where $W_{A}$ and $W_{B}$ are the abundances of the two phases; $F_{A}$ and $F_{B}$ the structure factors related to the two phases; $d(A)_{1}\left(d(B)_{j}\right)$ the possible distances between the layers of the phase $\mathrm{A}(\mathrm{B}) ; p(A)_{2}\left(p(B)_{j}\right)$ the probabilities of going from one layer of a thickness $d(A),(d(B)$,$) in the A(B)$ phases to another in same phase; $P_{A, B}$ the probability of going from one layer in the phase $\mathrm{A}$ to another in the phase $\mathrm{B}\left(P_{A, A} P_{B, A}\right.$ and $P_{B, B}$ are defined in the same way).

The relationships between proportions of the two phases and probabilities are given by :

$$
W_{A}+W_{B}=1 ; P_{A, A}+P_{A, B}=1 ; P_{B, A}+P_{B, B}=1 ; W_{A} P_{A, B}=W_{B} P_{B, A}
$$




$$
\sum_{i} p(A)_{\imath}=1 ; \sum_{j} p(B)_{j}=1
$$

In this study we consider a random interaction between swelling phases which are limited to 0,1 and 2 water layers. In this case, the abundance $w_{1}\left(w_{j}\right)$ of one interlayer distance in a given phase can be written:

$$
w_{1}=P_{A, A} p(A)_{i} ; w_{\mathrm{J}}=P_{B, B} p(B)_{\jmath}
$$

It is possible to define the mean interlayer distance :

$$
\bar{d}=\sum_{1} w_{1} d(A)_{1}+\sum_{j} w_{j} d(B)_{j}
$$

and a disorder parameter [7] :

$$
\frac{\bar{\delta}^{2}}{\bar{d}^{2}}=\frac{\sum_{t} w_{1}\left(d(A)_{t}-\bar{d}\right)^{2}+\sum_{j} w_{j}\left(d(B)_{j}-\bar{d}\right)^{2}}{\bar{d}^{2}}
$$

\subsection{Water content calculations}

Numcrous works $[5,6,8,9]$ have shown that different types of water could be defined. We will call "total internal water" the water contained in the swelling phase of clay particles. It is the sum of the water contained in the interlayer space (water layers) and the water contained in the internal porosity ((inside the particle, Fig. 3). The external water is all the remaining water (outside the particle).

The probability of finding $\mathrm{k}$ water layers between 2 adjacent layers is given by the total abundance of layers with $\mathrm{k}$ water layers $\boldsymbol{w}_{\mathrm{k}}$.

The water content $W C_{k C}$ (expressed in water gram by clay gram) in an interlayer space corresponding the probability $w_{k C}$ i.e. to a interlayer distance $d_{k C}$ is given by [8] :

$$
W C_{k C}=\frac{S p(t o t) \times(M-1) \times w_{k C} \times\left(d_{k C}-d_{c o l}\right) \times 10^{-4}}{2 M}
$$

where $S p(t o t)=800 \mathrm{~m}^{2} / \mathrm{g}$ [6] is the total specific area and $d_{c o l}$ the distance between two layers in a collapsed phase $\left(d_{c o l}=9.6 \AA,[6]\right)$.

\section{EXPERIMENTAL}

The smectites sample submitted to the dehydroxylation-rehydroxylation process were Namontmorillonites sample from Wyoming (Wy) and Camp Bertaux (CB) and a beidellite sample from Unterrupsroth (Un) (Table 1). To get the dehydroxylated state, the natural (N) sample was heated with a $100^{\circ} \mathrm{C}$ /hour heating rate to $750^{\circ}$, kept at this temperature during 1 hour, and then cooled in air. For rehydroxylation a gold capsule was filled with $50 \mathrm{mg}$ of the dehydroxylated sample plus $15 \%$ in weight of water. The capsule was placed in a Tuttle type pressure vessel at $350^{\circ} \mathrm{C}, 1 \mathrm{kbar}$ for 5 days. After removal from the pressure vessel, the rehydroxylated $(\mathrm{R})$ sample was heated at $120^{\circ} \mathrm{C}$ during 4 hours to extract excess water. The $R$ sample has been studied in air dried state.

Thermogravimetric analyses were performed using a Setaram TGA 92 microanalyser, with a heating rate of $10^{\circ} \mathrm{C} /$ minute, using $30 \mathrm{mg}$ of sample for each measurement. The derived curves of the TGA patterns were drawn to compare the weight loss, assigned to hydroxyl water, in the natural and rehydroxylated states. 
X-ray diffraction intensity data were recorded on a SAXS setup using a RIGAKU rotating anode (12 kW) with a curved germanium monochromator $\left(\mathrm{CuK}_{\alpha}=1.5405 \AA\right)$. The monochromatic beam is convergent in the horizontal plane and diverging in the vertical plane. It is possible to obtain a punctual collimation simply by limiting the height of the beam by a pair of horizontal tentalum slits. Under such consideration, the direct beam dimensions at the focalization point are $300 \mu \mathrm{m}$ by $500 \mu \mathrm{m}$. Alignment and calibration are performed using the 001,002 and 003 reflections of tetradecanol powder [10]. The cell used is made of aluminium, with mica windows. The surface of the irradiated sample is $0.5 \mathrm{~mm}$ by $1 \mathrm{~mm}$. All the experiments had to be carried out at room temperature.

Table 1. Cation composition of the sample under study calculated per $\mathrm{O}_{10}(\mathrm{OH})_{2}$. Composition cationique de l'échantillon étudié.

\begin{tabular}{cccccccc}
\hline Sample & Interlamellar cation & \multicolumn{2}{c}{ Tetrahedral cations } & \multicolumn{4}{c}{ Octahedral cations } \\
\cline { 2 - 8 } & $\mathrm{Na}$ & $\mathrm{Si}$ & $\mathrm{Al}^{\mathrm{IV}}$ & $\mathrm{Al}^{\mathrm{VI}}$ & $\mathrm{Fe}^{3+}$ & $\mathrm{Mg}^{2+}$ & $\mathrm{Ti}^{4+}$ \\
\hline $\mathrm{Wy}$ & 0.29 & 3.96 & 0.04 & 1.53 & 0.18 & 0.26 & 0.01 \\
$\mathrm{CB}$ & 0.34 & 3.99 & 0.01 & 1.45 & 0.22 & 0.33 & \\
$\mathrm{Un}$ & 0.43 & 3.55 & 0.44 & 1.76 & 0.01 & 0.27 & \\
\hline
\end{tabular}

\section{RESULTS}

\subsection{Thermogravimetric analyses}

The thermo-gravimetric analysis (TGA) shows a change in the dehydroxylation temperature which decrease strongly from the natural specimens to the rehydroxylated samples. This shift is clearly related to the change in the $\mathrm{OH}-\mathrm{OH}$ distance, which is longer in $c v$ layers (Fig. 2a) in comparison with $t v$ ones (Fig. 2b) $[2,3]$. The dehydroxylation-rehydroxylation process keeps the original periodicity of the samples but induces a transformation of the layers into $t v$ oncs $[2,3]$. An example is given in the Fig.4; the DT curve of the Na-Wyoming montmorillonite sample contains one strong maximum at $700^{\circ} \mathrm{C}$. It corresponds to the dehydroxylation of $c v 2: 1$ layers $[1,2,3]$. In contrast, the dehydroxylation of the $R$ sample takes place at a lower temperature $\left(540^{\circ} \mathrm{C}\right)$ and corresponds of $t v$ layers [3].

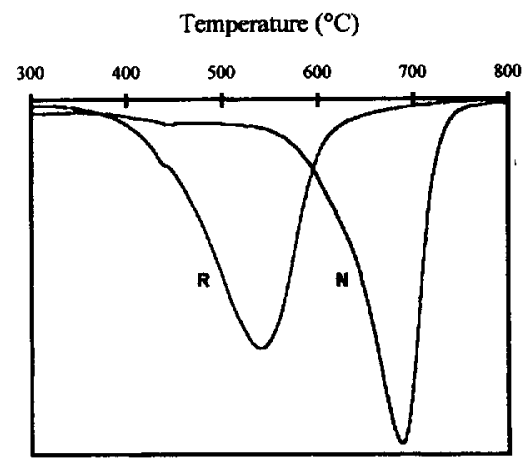

Figure 4: Derived curve of the TGA patterns of the Na-Wyoming montmorillonite sample in natural state (N) and in rehydroxylated state $(R)$.

Dérivées des courbes d'analyse thermique gravımétrique de l'échantillon de montmorillonite sodique du Wyoming dans l'état naturel $(\mathrm{N})$ et dans l'état réhydroxylé $(\mathrm{R})$. 


\subsection{SAXS patterns analyses}

An examination of the experimental SAXS patterns (Fig.5a and b) shows some modulations of the intensity situated between 5 and $8^{\circ} 2 \theta$. These results indicate that the $\mathrm{N}$ or $\mathrm{R}$ samples have a structure of hydrated solids in which occur short-distance interactions between first neighbors $[4,6,8]$. The sample consists of a set of particles, connected or not, created by the more or less disordered stacking of hydrated layers with a limited number of interlayer water layers $(0,1,2$ or 3$)$. The apparent interlayer distances $\left(d_{a p}\right)$ before and after the dehydroxylation-rehydroxylation cycle are very similar. The width of the modulation increase in this $\mathrm{R}$ specimens in comparison with the $\mathrm{N}$ ones. These result confirm the previous studied on this subject [3]. Note the presence of a relatively fine additional reflection at $d_{a p}=$ $12.5 \AA$ in the CB R sample.
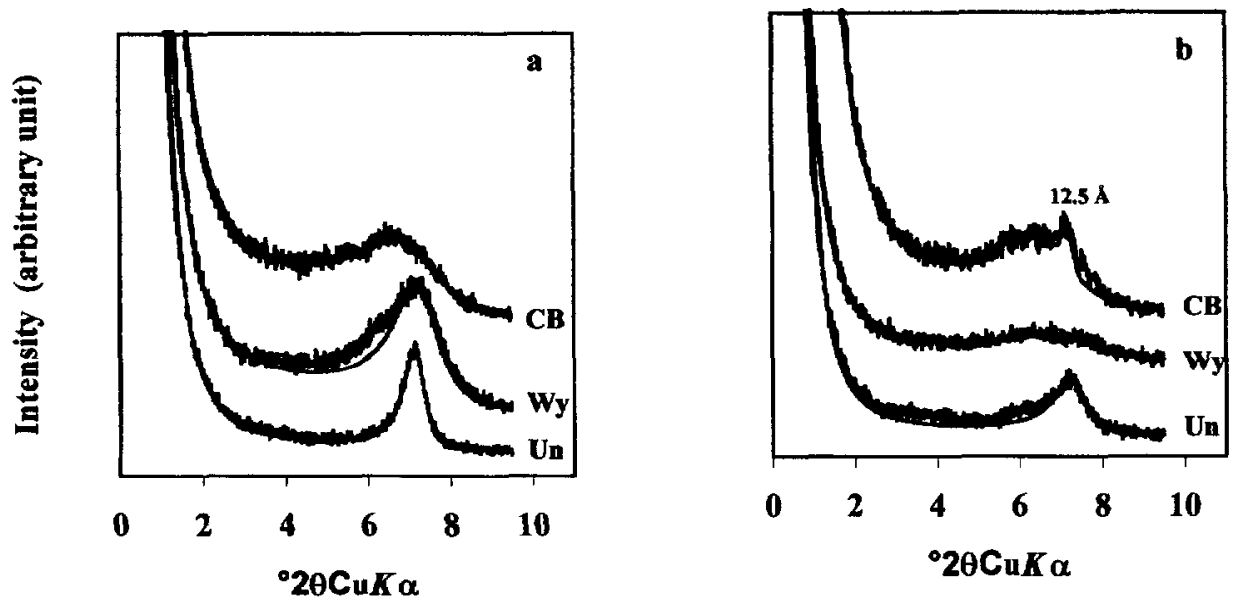

Figure 5: SAXS experimental and calculated patterns for the three samples in the natural (a) and rehydroxylated (b) states. Diagrammes DPAX expérimentaux et calculés pour les trois ćchantillons dans les états naturel (a) et réhydroxylé (b)

Table 2 presents the value of the different structural parameters $\bar{d}, \bar{M}$ and disorder, determined by adjusting the theoretical spectra (obtained from the structural model described above) to the experimental ones (Fig. 5). The $d_{k C}$ values used for the $\bar{d}$ calculations are given by Berend [11] and Ben Brahim [12].

Table 2. Water contents, structural parameters deduced from SAXS patterns modelisation.

Contenus en eau et paramères structuraux obtenus par modélisation des diagrammes de DPAX.

\begin{tabular}{lccccccccccc}
\hline & \multicolumn{3}{c}{ Interlayer hydration } & \multicolumn{3}{c}{ Structural parameter } & \multicolumn{3}{c}{ Water contents } \\
\cline { 2 - 11 } & $w_{0 \mathrm{C}}$ & $w_{1 \mathrm{C}}$ & $w_{2 C}$ & $\bar{d}(A)$ & $d_{a p}(A)$ & $\bar{M}$ & Disorder & $W C_{J C}$ & $W_{C_{2 C}}$ & $W C_{t}$ \\
& & & & & & & & & & \\
\hline Wy N & 0.35 & 0.49 & 0.16 & 12.1 & 12.2 & 200 & 0.024 & 0.056 & 0.038 & 0.094 \\
Wy R & 0.55 & 0.18 & 0.27 & 11.9 & 12.9 & 200 & 0.040 & 0.020 & 0.064 & 0.084 \\
CB N & 0.47 & 0.24 & 0.29 & 12.1 & 13.1 & 80 & 0.034 & 0.027 & 0.065 & 0.092 \\
CB R & 0.48 & 0.13 & 0.39 & 12.4 & 13.8 & 40 & 0.039 & 0.014 & 0.086 & 0.100 \\
Un N & 0.17 & 0.71 & 0.12 & 12.4 & 12.3 & 45 & 0.014 & 0.079 & 0.028 & 0.107 \\
Un R & 0.28 & 0.58 & 0.14 & 12.2 & 12.2 & 130 & 0.020 & 0.066 & 0.033 & 0.099 \\
\hline
\end{tabular}

WC, total water content 


\section{DISCUSSION AND CONCLUSIONS}

For the three samples, the treatment is responsible of a perceptible increasing of the disorder parameter (Table 2, Fig. 6). These results can be predicted because the increasing of the width of the reflections (Fig. 5). Table 2 shows that, after a dehydroxylation-rehydroxylation cycle, the number of layers with zero water layer increase. The behaviour of the CB sample is distinguishable from others; $w_{0 \mathrm{C}}$ slightly differs between the $\mathrm{N}(0.47)$ and the $\mathrm{R}(0.48)$ states in comparison with the two others samples (see Table 2). The main characteristic of the $C B$ sample is the exclusive localization of the deficit of charge in the octahedral sheet (Table 2). This can be associated to the small variations of $w_{0 c}$ in comparison with samples containing no negligible deficit of charge in tetrahedral sites. The weak evolution of $w_{0 c}$ in the CB sample can explain the increasing of the total water content in the interlayer space which evolve in a opposite direction in comparison with Wy and Un samples. This results permit to assume that the treatment efficiency for the hydration properties is connected to the localization of cation substitutions in the tetrahedral sheets.

The decreasing of the disorder parameter with the proportion of tetrahedral charge (Fig.6) shows that, in particle, the distribution of water layers depend on the localization of the deficit of charge. Localization of cation substitutions in the tetrahedral sheets is a propitious factor for the order in the organization of the mineral.

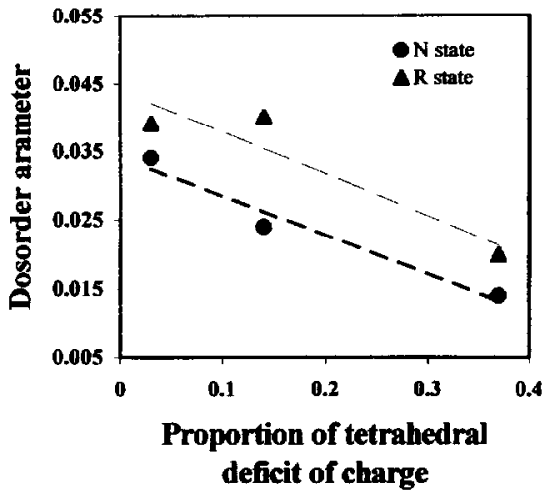

Figure 6: Evolution of the disorder parameter with the proportion of the tetrahedral charge in the natural (N) and rehydroxylated $(R)$ states rẻhydroxylé $(\mathbf{R})$.

Evolution du paramètre de désordre avec la proportion de charge tetraédriques dans les états naturel (N) et

\section{References}

1. V.A. Drits, G. Besson, F. Muller, Clays Clay Miner., 43, 718-731 (1995).

2. F. Muller, V.A. Drits, A. Plançon, J-L. Robert, Clays Clay Miner., 48, 572-585 (2000).

3. F. Muller, A. Plançon, V.A. Drits, J.Phys. IV, 10, 481-487 (2000).

4. C-H. Pons, F. Rousseaux, D. Tchoubar, Clay Miner., 16, 23-42 (1981).

5. O. Touret, C-H. Pons, D. Tessier, Y. Tardy, Clay Miner., 25, 217-233 (1990).

6. H. Gaboriau, in Ph.D. thesis, (University of Orléans, France, 1991).

7. J. Saez-Aumon, C-H. Pons, J-Z. Iglesias, J-A. Raussel-Colom, J. App. Cryst., 16, 439-448 (1983).

8. H. Ben Raheim, D. Tessier, C-H. Pons, Clay Miner., 21, 9-29 (1986).

9. K. Faisandier, C-H. Pons, D. Tchoubar, F. Thomas, Clays Clay Miner., 46, 636-648 (1998).

10. G-W. Brindley, Clays Clay Miner., 29, 67-68 (1981).

11. I. Berend, in Ph.D. thesis, (I.N.P.L. Nancy, France,1991).

12. J. Ben Brahim, in ès Sciences Doctorate thesis, (University of orléans, France, 1985). 